\title{
Non-surgical management of Boerhaave's syndrome: a case series study and review of the literature
}

\section{(ㄷ)(1)}

Authors

Khalil Aloreidi ${ }^{1}$, Bhavesh Patel ${ }^{2}$, Tim Ridgway ${ }^{2}$, Terry Yeager ${ }^{3}$, Muslim Atiq ${ }^{2}$

Institutions

1 Department of Internal Medicine, University of South Dakota - Sanford School of Medicine, Sioux Falls, South Dakota, United States

2 Department of Gastroenterology, University of South Dakota - Sanford School of Medicine, Sioux Falls, South Dakota, United States

3 Department of Interventional Radiology, University of South Dakota - Sanford School of Medicine, Sioux Falls, South Dakota, United States

submitted 9.6.2017

accepted after revision 31.8.2017

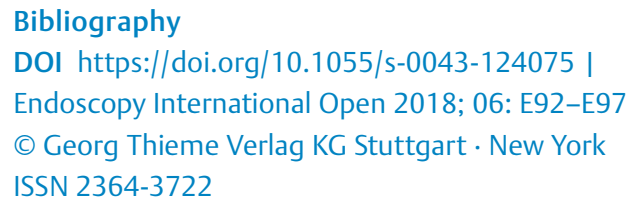

\section{Corresponding author}

Khalil Aloreidi, Internal Medicine Residency program, University of South Dakota - Sanford School of Medicine, 1400 West 22nd Street Sioux Falls, SD 57105

Fax: +1-605-357-1365

khalil.aloreidi@usd.edu

\section{ABSTRACT}

Background and study aims Boerhaave's syndrome (BS) is a life-threatening condition with morbidity and mortality rates as high as $50 \%$ in some reports. Until recently, surgical intervention has been the mainstay of management plans. With advances in therapeutic endoscopy, however, there has been increasing interest in non-surgical options including endoscopic esophageal stenting.

Patients and methods We reviewed the medical records of all patients diagnosed with BS and managed with endoscopic interventions between November 2011 and November 2016. The following variables were collected: patient demographics, clinical presentations, locations of esophageal perforation, primary interventions, complications, and outcomes.

Results Six patients were found to be diagnosed with BS during the study period. The median age at presentation was 55. There were 4 males and 2 females. The most common site of perforation was in the distal esophagus. The most common presenting symptom was chest pain (67\%) following an episode of vomiting or retching. Four patients (66.7\%) developed septic shock. Endoscopic treatment with a fully covered esophageal stent was the primary intervention in all patients (100\%). Interventional radiology was consulted in all cases for fluid drainage and chest tube placements. Clinical resolution of the BS was achieved in all patients $(100 \%)$ without any subsequent surgical interventions. There were no deaths within the study group, and the average follow-up duration was 2 years.

Conclusion Endoscopic treatment seems to be an effective management strategy in patients with BS. We also noted satisfactory results in patients presenting with sepsis, presumably due to urgent, interventional radiology-guided fluid drainage.

\section{Introduction}

Boerhaave's syndrome (BS), or spontaneous esophageal perforation due to high intraesophageal pressure, is a life-threatening condition with high morbidity and mortality. Delayed diagnosis is associated with mortality as high as $30 \%$ to $50 \%$ [1]. Until recently, surgical intervention has been the mainstay of treatment. Surgery in acute presentations, though, carries a high burden of complications. With advances in therapeutic endoscopy, there has been an evolving interest in the use of techniques such as esophageal stent placement and/or endoscopic suturing in combination with interventional radiology (IR)-guided techniques.

\section{Patients and methods}

We reviewed the medical records of all patients who underwent endoscopic interventions for esophageal perforations between November 2011 and November 2016. We collected the data on patients who received BS as their diagnosis upon presentation. 
- Table 1 Patient details.

\begin{tabular}{|c|c|l|l|l|l|l|}
\hline Case & Age/sex & Comorbidity & Presentation & Diagnosis & Sepsis & Organ failure \\
\hline 1 & $42 \mathrm{M}$ & $\begin{array}{l}\text { Cirrhosis, Barrett's esophagus, GERD, } \\
\text { asthma }\end{array}$ & 3 days & 40 hours & Septic shock & Respiratory/renal failure \\
\hline 2 & $57 \mathrm{~F}$ & $\begin{array}{l}\text { Barrett's esophagus, Nissen fundoplication, } \\
\text { asthma }\end{array}$ & 2 days & 6 days & Septic shock & Respiratory failure \\
\hline 3 & $67 \mathrm{M}$ & Diabetes mellitus, Barrett's esophagus & 1 day & $<24$ hours & sepsis & Respiratory failure \\
\hline 4 & $55 \mathrm{M}$ & $\begin{array}{l}\text { Eosinophilic esophagitis, Barrett's } \\
\text { esophagus, Nissen fundoplication }\end{array}$ & 3 hours & 1 hour & Sepsis & None \\
\hline 5 & $54 \mathrm{M}$ & Alcohol abuse, GERD, rheumatoid arthritis & 2 days & 1 day & Septic shock & Respiratory/renal Failure \\
\hline 6 & $24 \mathrm{~F}$ & Diabetes mellitus, gastroparesis & 3 days & 1 day & Septic shock & Respiratory/renal failure \\
\hline
\end{tabular}

- Table 2 Patient intervention and outcome.

\begin{tabular}{|c|c|c|c|c|c|c|}
\hline Case & $\begin{array}{l}\text { Perfora- } \\
\text { tion size }\end{array}$ & Intervention & $\begin{array}{l}\text { Stent duration } \\
\text { (days) }\end{array}$ & $\begin{array}{l}\text { Hospital } \\
\text { stay (days) }\end{array}$ & Stricture & $\begin{array}{l}\text { Patient status } \\
\text { (after } 2 \text { years) }\end{array}$ \\
\hline 1 & $6 \mathrm{~cm}$ & $23 \mathrm{~mm} \times 12.5 \mathrm{~cm}$ WallFlex fully-covered Stent & 156 & 14 & No & Alive \\
\hline 2 & $1 \mathrm{~cm}$ & $23 \mathrm{~mm} \times 12.5 \mathrm{~cm}$ WallFlex fully-covered Stent & 6 & 21 & No & Alive \\
\hline 3 & $1 \mathrm{~cm}$ & $23 \mathrm{~mm} \times 12.5 \mathrm{~cm}$ WallFlex fully-covered Stent & Lost Follow up & 17 & No & Alive \\
\hline 4 & $4 \mathrm{~cm}$ & $23 \mathrm{~mm} \times 12.5 \mathrm{~cm}$ WallFlex fully-covered Stent & 35 & 14 & No & Alive \\
\hline 5 & $1.5 \mathrm{~cm}$ & $23 \mathrm{~mm} \times 15.5 \mathrm{~cm}$ WallFlex fully-covered Stent & 60 & 33 & Yes & Alive \\
\hline 6 & $2 \mathrm{~cm}$ & $18 \mathrm{~mm} \times 12.3 \mathrm{~cm}$ WallFlex fully-covered Stent & 76 & 46 & No & Alive \\
\hline
\end{tabular}

The following variables were collected: patient demographics, clinical presentations, time to diagnosis and endoscopic intervention from presentation, locations of esophageal perforation, primary interventions, any other subsequent interventions or supportive measures, complications, and outcomes.

\section{Results}

We identified a total of 6 patients ( $\triangle$ Table 1 ) who received nonsurgical management of BS during the 5 years' time period. The median age at presentation was 55 . There were 4 males and 2 females. The most common site of perforation was in the distal esophagus, just proximal (within $3 \mathrm{~cm}$ ) to the gastroesophageal junction. The most common presenting symptom was chest pain (67\%) following an episode of vomiting or retching. Three patients $(50 \%)$ had underlying Barrett's esophagus. Four patients $(66.7 \%)$ developed septic shock requiring inotropic support, while 5 patients (83.3\%) developed respiratory failure requiring mechanical ventilation support. These patients mostly presented 2 to 3 days after the development of symptoms. Endoscopic treatment with a fully covered esophageal stent was the primary intervention used for all of these patients $(100 \%)$. IR was consulted for all patients. IR-guided interventions were aimed at drainage of the mediastinal/pleural fluid collection. Three patients required re-stenting (50\%). Two of them was due to stent migration and 1 due to continuous leakage at the perforation site. Endostiches and clips were used on these cases to prevent subsequent migration. Four patients required subsequent feeding tube placement, either jejunostomy or gastrostomy. Clinical resolution of the BS was achieved in all patients $(100 \%)$ without any subsequent surgical interventions ( Table 2). All the patients were discharged home following a median hospital stay of 19 days. There were no deaths within the study group. The average follow-up duration was 2 years.

\section{Discussion}

After its initial description in 1724, BS has come to be considered the most lethal gastrointestinal perforation, with a mortality rate of close to $100 \%$ without treatment. BS may be difficult to diagnose up front, with the possibility of an erroneous diagnosis at presentation in almost half of reported cases. In $90 \%$ of the cases, the rupture is in the lower third of the esophagus and in the left lateral position. This is believed to be due to anatomic weakness.

Presenting symptoms for BS include vomiting (84\%), thoracic pain $(79 \%)$, dyspnea (53\%), epigastric pain $(47 \%)$, or dysphagia (21\%). Mackler's triad (thoracic pain, vomiting, and emphysema) is highly suggestive of BS, but this was found only in onethird of the cases. A physical examination may reveal subcutaneous emphysema and signs related to the development of hydropneumothorax. A radiographic examination may reveal pneumomediastinum ( $\triangleright$ Fig.1), pleural effusion, hydropneu- 

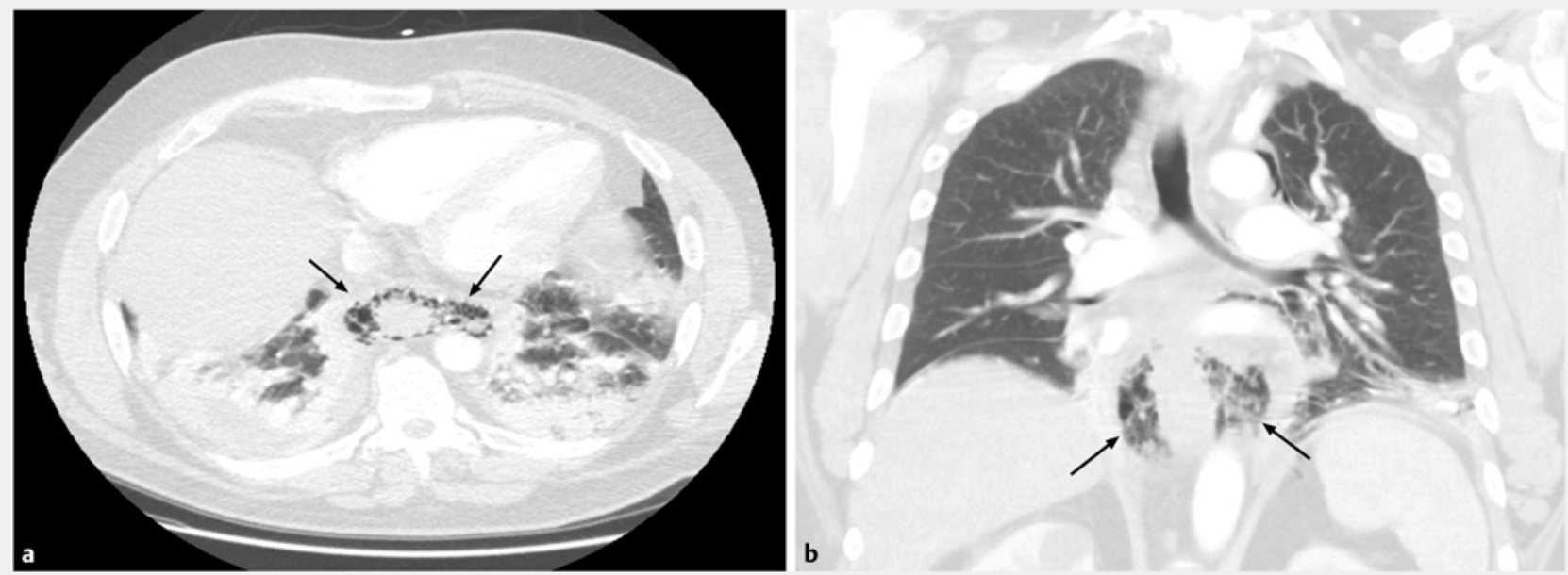

- Fig. 1 CT scan showing pneumomediastinum (Arrows) in the lower part of esophagus at the site of perforation in both Axial (a) and Coronal (b) view.
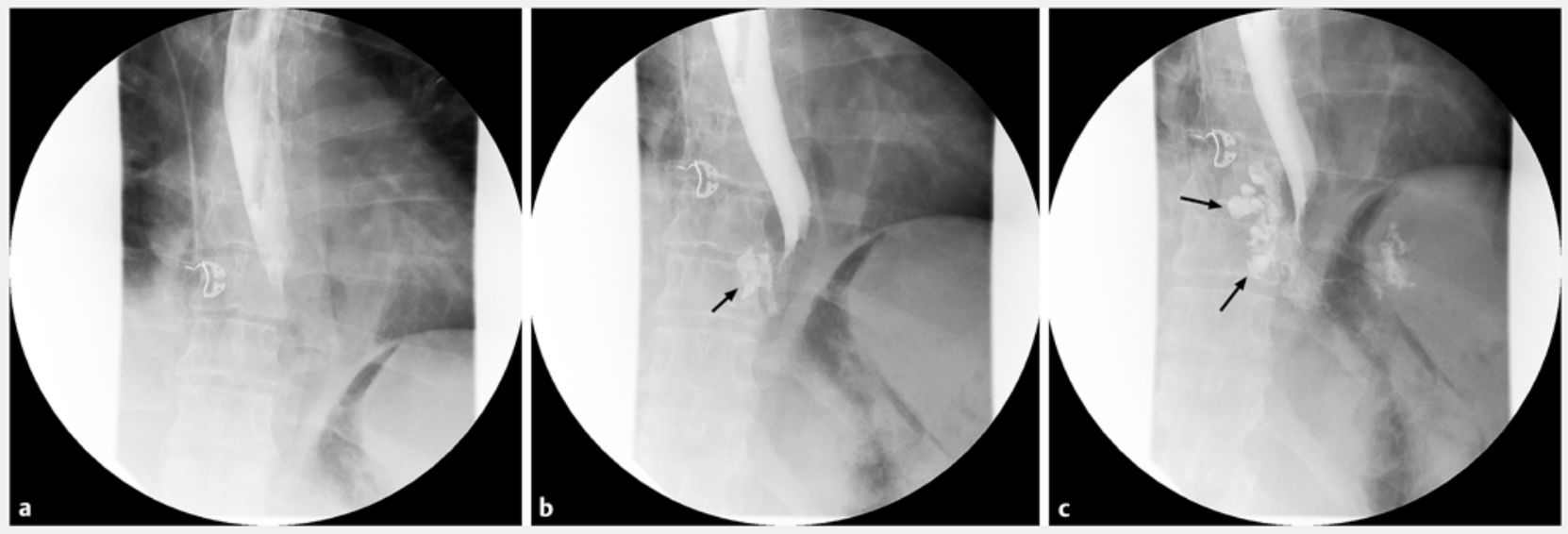

Fig.2 Esophagogram (a) showing leakage of water soluble contrast material (arrows) into the right side of the chest and/or mediastinum $(\mathbf{b}, \mathbf{c})$.

mothorax, subcutaneous emphysema, and subdiaphragmatic air. However, it can be normal in around $12 \%$ of patients.

The gold standard for the diagnosis of BS is an esophagogram with a water-soluble contrast ( $\mathbf{F i g . 2}$ ), which has a false-negative rate of up to $10 \%$. However, computer tomography with an oral contrast is able to illustrate a perforation and the surrounding inflammatory process (e.g., mediastinitis). Most authors recommend upper endoscopy to confirm BS ( Fig.3) with a sensitivity and specificity of $100 \%$ and $83 \%$, respectively [2]. There is, though, concern regarding increasing the size of the existing defect.

The treatment paradigm for BS seems to be evolving with less invasive modalities being introduced. Data on these newer and less invasive treatments are limited, as BS is a relatively uncommon condition. Moreover, it mostly occurs as a life-threatening emergency, which requires emergent actions to avoid fatal outcomes. Therefore, randomized prospective trials are difficult to implement. Further, most of the available literature on the treatment of esophageal ruptures is not specifically about BS and instead includes mostly cases of esophageal perforation or leaks. Interestingly, a BS diagnosis is usually delayed compared to iatrogenic rupture diagnosis because of the vague clinical picture, and this has detrimental effects on survival.

The available therapeutic options for BS mainly include conservative approaches with supportive and expectant management plans, as well as endoscopic or surgical interventions. Most of the previously published studies have established the time period between the onset of symptoms and diagnosis (less than 24 hours or greater than 24 hours) as the major factor influencing morbidity, mortality, and the overall outcome [3]. That is evident in our study group, as the patients who presented late had more complications like septic shock and empyema that affected the clinical success of treatment and the length of their hospital stay ( $\vee$ Table 1 ). 

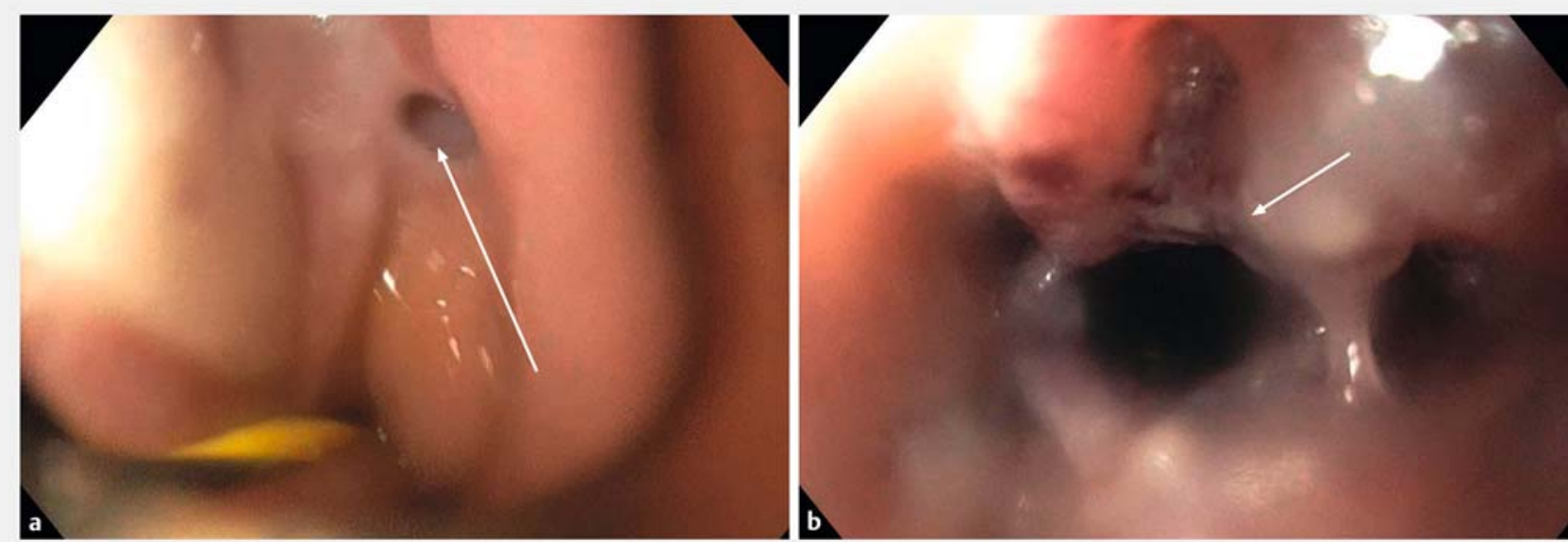

- Fig. 3 Endoscopic images showing esophageal tear in patients with BS (a, b).
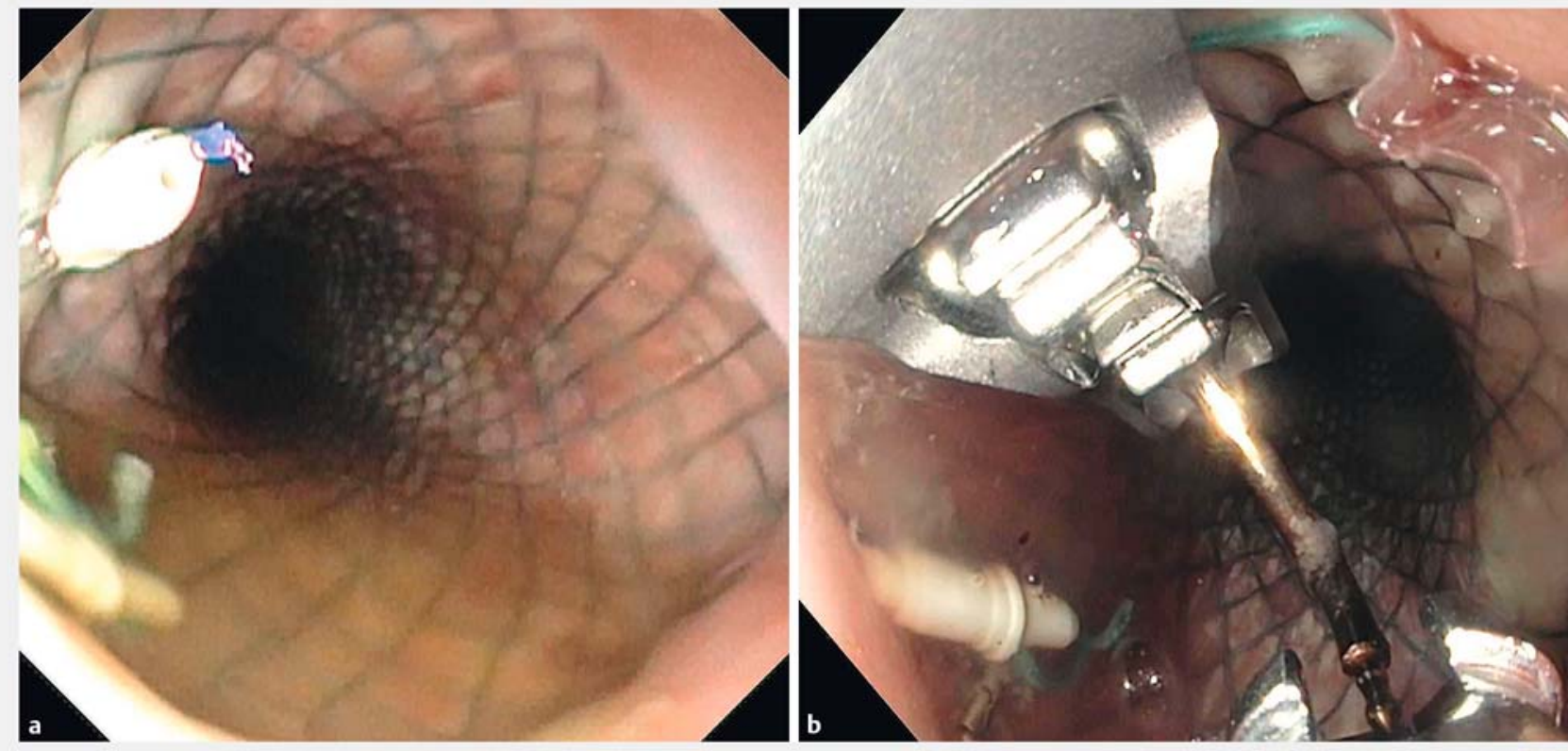

- Fig.4 Endoscopic images showing implemented esophageal stents with various techniques to prevent stent migration. In the first image (a) the stent was fixed using a clip. In the second image (b) the stent was fixed using Endostitch.

In general, the conservative treatment plan consists of strict oral intake; the initiation of feeding enterostomy or total parenteral nutrition; an intravenous, broad-spectrum antibiotic; and intravenous administration of proton pump inhibitors as well as fluids. The mortality rate with these measures in selected cases was reported to be between $20 \%$ and $22 \%$ [4].

Surgical intervention retains a dominant role in management, and this includes esophageal resection or chest drainage with or without esophageal repair. The primary repair of an esophageal perforation remains the gold standard of therapy, with a $94.7 \%$ survival rate, provided the treatment is performed within 24 hours in the absence of esophageal diseases [4].
The use of self-expanding metal stents as a palliative measure for esophageal malignancies is well established and effective [5]. There is growing interest in the use of self-expanding covered metal stents in benign esophageal perforation, including BS. The endoscopic treatment aims mainly to prevent continued septic contamination and to guide the re-epithelialization of the esophageal mucosa with the esophageal stent placement ( $\mathbf{F i g . 4 )}$ and/or endoscopic suturing. Closure of the mucosal defect also allows for early oral feeding. In addition, it results in a great reduction in morbidity and mortality associated with the surgical repair of esophageal perforations [6]. A stent placement was first reported for spontaneous 
- Table 3 All cases published on endoscopic treatment of Boerhaave's syndrome.

\begin{tabular}{|c|c|c|c|c|c|c|c|}
\hline Author & $\begin{array}{l}\text { \# of } \\
\text { cases }\end{array}$ & Age & Type of stent & $\begin{array}{l}\text { Injury to } \\
\text { stenting }\end{array}$ & $\begin{array}{l}\text { Stent placement } \\
\text { duration }\end{array}$ & $\begin{array}{l}\text { Follow-up } \\
\text { period }\end{array}$ & $\begin{array}{l}\text { Complications and } \\
\text { outcome }\end{array}$ \\
\hline $\begin{array}{l}\text { Dumonceau, et al. } 1996 \\
\text { [11] }\end{array}$ & 1 & 63 & Ultraflex & 8 weeks & 40 weeks & 10 months & $\begin{array}{l}\text { Recurrent stricture } \\
\text { and fistula }\end{array}$ \\
\hline Eubanks, et al. 1999 [12] & 1 & 61 & Ultraflex & 2 weeks & 8 weeks & 8 months & Asymptomatic \\
\hline Yuasa, et al. 1999 [13] & 1 & 56 & Ultraflex & 1 weeks & 1 months & 6 months & $\begin{array}{l}\text { Dysphagia due } \\
\text { stricture }\end{array}$ \\
\hline Davies, et al. 1999 [14] & 1 & 85 & WallFlex & 2 weeks & 4 weeks & 8 weeks & Asymptomatic \\
\hline Chung, et al. 2001 [15] & 3 & $55-58$ & Song/Niti-S & $\begin{array}{l}4 \text { days to } \\
4 \text { weeks }\end{array}$ & $8-42$ weeks & $\begin{array}{l}6-32 \\
\text { months }\end{array}$ & Asymptomatic \\
\hline Fischer, et al. 2006 [16] & 5 & $44-77$ & Ultraflex & $\begin{array}{l}12-120 \\
\text { hours }\end{array}$ & $3-4$ weeks & 2 months & $\begin{array}{l}1 \text { died, others } \\
\text { asymptomatic }\end{array}$ \\
\hline Ghassemi, et al. 2007 [17] & 1 & 91 & Polyflex & 10 days & 10 weeks & 1 month & Asymptomatic \\
\hline Freeman, et al. 2009 [18] & 19 & $26-69$ & Polyflex & $\begin{array}{l}6-78 \\
\text { hours }\end{array}$ & $14-32$ days & 3 months & $\begin{array}{l}\text { Leaks, stent migra- } \\
\text { tion, no death }\end{array}$ \\
\hline $\begin{array}{l}\text { Koivukangas, et al. } 2012 \\
\text { [19] }\end{array}$ & 14 & $47-81$ & $\begin{array}{l}\text { Hanarostent/ } \\
\text { Microtec }\end{array}$ & $\begin{array}{l}8-280 \\
\text { hours }\end{array}$ & $13-59$ days & 6 months & $\begin{array}{l}2 \text { died, others } \\
\text { asymptomatic }\end{array}$ \\
\hline Darrien, et al. 2013 [20] & 5 & $30-75$ & Polyflex & $\begin{array}{l}24-72 \\
\text { hours }\end{array}$ & 6 weeks & 109 days & $\begin{array}{l}1 \text { died, } 2 \text { had } \\
\text { strictures }\end{array}$ \\
\hline Ota, et al. 2014 [21] & 1 & 56 & CHOOSTENT & - & 31 days & - & Asymptomatic \\
\hline $\begin{array}{l}\text { Van Weyenberg, et al. } \\
2014 \text { [22] }\end{array}$ & 1 & 51 & Hanaro & - & 6 weeks & 6 months & Asymptomatic \\
\hline $\begin{array}{l}\text { González-Haba, et al. } \\
2016 \text { [23] }\end{array}$ & 6 & 63 & $\begin{array}{l}\text { Fully covered } \\
\text { stent }\end{array}$ & - & 8 weeks & - & Asymptomatic \\
\hline
\end{tabular}

esophageal rupture in 1995 [7], when a plastic-covered, self-expanding stent was used and the patient was discharged 15 days later. Unfortunately, the patient died of massive hematemesis as a result of esophageal necrosis about 8 weeks following the procedure.

The main drawbacks of stent placement are migration of the stent; adverse effects of the endoprosthesis on normal esophageal tissues, including pressure-induced ischemia, ulceration, and perforation; development of new reactive stenosis at the ends of the endoprosthesis; bleeding or injury upon removal; and unsuccessful retrieval of the device at a later date. When stents are placed at the esophagogastric junction, reflux esophagitis is an additional concern. In our case series, we addressed some of these issues by using endostitch to prevent stent migration and using a stent with low radial outward pressure to minimize normal tissue injury. In addition, all of our patients underwent percutaneous drainage of pleural effusion, empyema, and mediastinal abscess on a priority basis.

In terms of type of stents used, Boeckel et al. [8] found no difference between self-expanding metal stents (SEMS) or plastic stents and a clinical success rate of $85 \%$ for different causes of esophageal perforation. Partially covered SEMS exhibit a favorable balance of a low migration rate and easy removability. Over-the-scope endoclips have been successfully used in the management of BS, provided the size of the perforation is less than $10 \mathrm{~mm}$.
Even though the earlier the intervention, the better clinical success and overall prognosis, 4 patients in our series who presented late and developed septic shock underwent endoscopic treatment with good outcomes. Still, they required prolonged hospitalization. Darrien et al. [9] published similar results in a case series of 5 patients who were all septic and managed with minimally invasive endoscopic therapies. Four patients survived, while the fifth died because of co-comorbidities. In fact, many other studies published on BS endoscopic treatment in general showed satisfactory outcome ( $\triangleright$ Table $\mathbf{3}$ ).

The point of importance to note here is that this challenges current belief that endoscopic therapy should be reserved for patients who present early and in whom there is no associated sepsis, as Dickinson et al. [10] conclude in their recently published study. They compared endoscopic therapy to surgery for BS in 2 groups of patients. Although all of the patients achieved clinical resolution, the mortality rate $(2 / 8)$ was higher, as well as the readmission rate (3/6), in the endoscopic therapy group. The inherent problem with this study and most BS studies is the sample size, as it is usually small. Also, we don't have much information about patient comorbidities and clinical presentations, and this information would help in determining a patient's prognosis, which could potentially affect the study results.

In conclusion, endoscopic treatment seems to be an effective management strategy for patients with BS. We also note 
the satisfactory results in patients presenting with sepsis with mediastinal or pleural abscesses, presumably due to urgent IRguided drainage and aggressive initial intensive care unit management.

\section{Competing interests}

None

References

[1] Pate JW, Walker WA, Cole FH et al. Spontaneous rupture of the esophagus: a 30-year experience. Ann Thorac Surg 1989; 47: 689692

[2] Vallböhmer D, Hölscher AH, Hölscher M et al. Options in the management of esophageal perforation: analysis over a 12-year period. Dis Esophagus 2010; 23: $185-190$

[3] Schweigert M, Beattie R, Solymosi N et al. Endoscopic stent insertion versus primary operative management for spontaneous rupture of the esophagus (Boerhaave syndrome): an international study comparing the outcome. Am Surg 2013; 79: 634-640

[4] Eroglu A, Can Kürkçüogu I, Karaoganogu N et al. Esophageal perforation: the importance of early diagnosis and primary repair. Dis Esophagus 2004; 17: 91 - 94

[5] Yakoub D, Fahmy R, Athanasiou T et al. Evidence-based choice of esophageal stent for the palliative management of malignant dysphagia. World J Surg 2008; 32: 1996 - 2009

[6] Hagel AF, Naegel A, Lindner AS et al. Over-the-scope clip application yields a high rate of closure in gastrointestinal perforations and may reduce emergency surgery. J Gastrointest Surg 2012; 16: 2132 - 2138

[7] Adam A, Watkinson AF, Dussek J. Boerhaave Syndrome: To Treat or Not to Treat by Means of Insertion of a Metallic Stent. Journal of Vascular and Interventional Radiology 1995; 6: 741 - 743

[8] van Boeckel PGA, Sijbring A, Vleggaar FP et al. Systematic review: temporary stent placement for benign rupture or anastomotic leak of the oesophagus. Aliment Pharmacol Ther 2011; 33: 1292-1301

[9] Darrien JH, Kasem H. Minimally invasive endoscopic therapy for the management of Boerhaave's syndrome. Ann R Coll Surg Engl 2013; 95: $552-556$
[10] Dickinson KJ, Buttar N, Wong Kee Song LM et al. Utility of endoscopic therapy in the management of Boerhaave syndrome. Endosc Int Open 2016; 4: E1146-E1150

[11] Dumonceau J-M, Devière J, Cappello $M$ et al. Endoscopic treatment of Boerhaave's syndrome. Gastrointestinal endoscopy 1996; 44: 477 479

[12] Eubanks PJ, Hu E, Nguyen D et al. Case of Boerhaave's syndrome successfully treated with a self-expandable metallic stent. Gastrointest Endosc 1999; 49: 780 - 783

[13] Yuasa N, Hattori T, Kobayashi Y et al. Treatment of spontaneous esophageal rupture with a covered self-expanding metal stent. Gastrointest Endosc 1999; 49: $777-780$

[14] Davies AP, Vaughan R. Expanding mesh stent in the emergency treatment of Boerhaave's syndrome. Ann Thorac Surg 1999; 67: 1482 1483

[15] Chung MG, Kang DH, Park DK et al. Successful treatment of Boerhaave's syndrome with endoscopic insertion of a self-expandable metallic stent: report of three cases and a review of the literature. Endoscopy 2001; 33: $894-897$

[16] Fischer A, Thomusch O, Benz S et al. Nonoperative treatment of 15 benign esophageal perforations with self-expandable covered metal stents. Ann Thorac Surg 2006; 81: 467-472

[17] Ghassemi KF, Rodriguez HJ, Vesga L et al. Endoscopic treatment of Boerhaave syndrome using a removable self-expandable plastic stent. J Clin Gastroenterol 2007; 41: 863-864

[18] Freeman RK, Van Woerkom JM, Vyverberg A et al. Esophageal stent placement for the treatment of spontaneous esophageal perforations. Ann Thorac Surg 2009; 88: $194-198$

[19] Koivukangas V, Biancari F, Meriläinen S et al. Esophageal stenting for spontaneous esophageal perforation. J Trauma Acute Care Surg 2012; 73: $1011-1013$

[20] Darrien JH, Kasem H. Minimally invasive endoscopic therapy for the management of Boerhaave's syndrome. Ann R Coll Surg Engl 2013; 95: $552-556$

[21] Ota K, Takeuchi T, Higuchi K. Temporary insertion of a covered selfexpandable metal stent for spontaneous esophageal rupture. Dig Endosc 2014; 26: $607-608$

[22] Van Weyenberg SJB, Stam F], Marsman W. Successful endoscopic closure of spontaneous esophageal rupture (Boerhaave syndrome). Gastrointest Endosc 2014; 80: 162

[23] González-Haba M, Ferguson MK, Gelrud A. Spontaneous esophageal perforation (Boerhaave syndrome) successfully treated with an overthe-scope clip and fully covered metal stent. Gastrointest Endosc 2016; 83: 650 